\title{
Differences in follicular morphology, steroidogenesis and oocyte maturation in naturally cyclic and PMSG/hCG-treated prepubertal gilts
}

\author{
T. Wiesak*, M. G. Hunter and G. R. Foxcroft* \\ AFRC Research Group on Hormones and Farm Animal Reproduction, University of Nottingham, \\ Faculty of Agricultural and Food Science, Sutton Bonington, LE12 5RD, UK
}

\begin{abstract}
Summary. Ovaries were obtained from naturally cyclic pigs on Days $16-17,18,19,20$ and 21 of the oestrous cycle and on the basis of observed follicular characteristics were assigned as representative of the early (Group 1), mid- (Groups 2 and 3) or late (after LH; Group 4) follicular phase. Follicular development in cyclic gilts was compared with that in ovaries obtained from late prepubertal gilts 36 (Group 5) or 72 (Group 6) $h$ after treatment with 750 i.u. PMSG alone, or with a combination of 500 i.u. hCG $72 \mathrm{~h}$ after PMSG and slaughter 30-40 h later (Group 7). After dissection of all follicles $>2 \mathrm{~mm}$ diameter, follicular diameter, follicular fluid volume, follicular fluid concentrations of progesterone, oestradiol and testosterone, and the stage of oocyte maturation were determined.

Combined PMSG/hCG treatment of immature gilts resulted in a pattern of follicular development different from that in naturally cyclic gilts during the follicular phase. Overall exogenous gonadotrophin treatment also increased $(P<0.001)$ the variability in follicular diameter and fluid volume. Comparisons between appropriate groups also established differences in the variability of both morphological (diameter and volume, Group 1 vs Group 5; $P<0.05$ ) and biochemical development (follicular fluid oestradiol, Group 3 vs Group 6 and Group 4 vs Group 7; both $P<0 \cdot 05$ ). Such differences in both morphological and biochemical characteristics between cyclic and PMSG/hCG-treated gilts were particularly evident in the population of larger $(>6 \mathrm{~mm})$ follicles.

These results indicate that the pattern of follicular development in naturally cyclic and in PMSG/hCG-treated gilts is dissimilar and suggests that the ovaries of gonadotrophin-treated prepubertal gilts are functionally different from the ovaries of mature females.
\end{abstract}

Key'words: follicle; gonadotrophins; steroids; pig

\section{Introduction}

In the pig, follicular recruitment from the proliferating pool occurs between Days 14 and 16 of the oestrous cycle. Foxcroft \& Hunter (1985) suggested that, as a consequence of follicles being recruited at different stages of development, follicular heterogeneity may persist into the late follicular phase. These authors also suggested that the dominant follicles in the pig may promote the maturation of smaller follicles during the selection process, in contrast to their inhibitory effect in

*Present address: Department of Animal Science, University of Alberta, 310 Agriculture/Forestry Building, Edmonton, Alberta, Canada T6G 2 P5. 
other species (Fortune \& Quirk, 1988; Driancourt \& Fry, 1988). Follicular enlargement and ovulation can be induced in immature gilts by the injection of PMSG alone, or in combination with hCG (see Ainsworth et al., 1980; Paterson, 1982; Christenson et al., 1985).

Although there are some suggestions that the ovary of naturally cyclic and gonadotrophintreated prepubertal pigs are different (Babalola \& Shapiro, 1988; Grant et al., 1989), experimental evidence involving a direct comparison of ovarian tissue during natural and PMSG/hCG-stimulated follicular development is lacking. The purpose of the present study, therefore, was to investigate whether the extent of follicular heterogeneity is dependent on the type of gonadotrophin stimulation received by the ovary and also whether the stage of oocyte maturation is functionally related to the stage of follicular development in the preovulatory period. This paper presents data on the morphological status of the ovary and accumulated steroids in follicular fluid and therefore represents an analysis of differences that reflect the in-vivo situation.

\section{Materials and Methods}

Animals. Mature $(\mathrm{N}=21)$ and prepubertal $(\mathrm{N}=18)$ Landrace $\times$ (Landrace $\times$ Large White) gilts from the University Farm were used in the experiment. Mature cyclic gilts were checked for oestrus, slaughtered and the ovaries recovered on predicted Day 16-17, 18, 19, 20 or 21 after detection of 2nd or 3rd oestrus.

Measurement of oestradiol- $17 \beta$ concentration in follicular fluid revealed marked variation in follicular maturation between animals slaughtered on the same predicted day of the cycle. For the purpose of statistical analysis cyclic pigs were therefore retrospectively assigned to groups on the basis of follicle size, follicular fluid oestradiol concentration and oocyte status as follows.

Group 1-pigs on predicted Days 16-18 of the oestrous cycle with small follicles $(<6 \mathrm{~mm})$ in the ovary and with low $(<100 \mathrm{ng} / \mathrm{ml})$ oestradiol concentration $(\mathrm{N}=5)$.

Group 2 pigs on predicted Days $18-20$ of the oestrous cycle with large $(6-8 \mathrm{~mm})$ follicles but still with low $(<100 \mathrm{ng} / \mathrm{ml})$ follicular fluid oestradiol $(\mathrm{N}=5)$.

Group 3-pigs on predicted Days 18-20 of the oestrous cycle with large $(6-8 \mathrm{~mm})$ follicles but with high $(>100 \mathrm{ng} / \mathrm{ml})$ follicular fluid oestradiol $(\mathrm{N}=5)$.

Group 4 - pigs on predicted Day $20-21$ of the oestrous cycle with the largest follicles $(>8 \mathrm{~mm}$ ), but with low follicular fluid oestradiol and oocytes at various stages of maturation, indicating the occurrence of the preovulatory LH surge $(\mathrm{N}=6)$. (In Groups 1, 2 and 3 oocytes were at the germinal vesicle (GV) stage.)

Gonadotrophin-treated prepubertal gilts received 750 i.u. PMSG s.c. alone (Intervet UK Ltd, Cambridge, UK) at $36 \mathrm{~h}(\mathrm{~N}=4$, Group 5) or $72 \mathrm{~h}(\mathrm{~N}=4$, Group 6) before slaughter, or at $72 \mathrm{~h}$ followed by 500 i.u. hCG s.c. (Sigma Chemical Co., Poole, UK) 35-40 h ( $\mathrm{N}=10$, Group 7) before slaughter to allow comparisons of ovarian development at the same stages of the follicular maturation.

Sample collection. Ovaries were collected within $15 \mathrm{~min}$ of slaughter and immediately transferred to the laboratory in ice-cold Hank's Balanced Salt Solution with $20 \mathrm{~mm}$-Hepes buffer ( $n$-2-hydroxyethylpiperazine- $n^{\prime}-2$ ethanesulphonic acid; both Flow Laboratories, Irvine, UK). All follicles $>2 \mathrm{~mm}$ in diameter were dissected. Follicular diameter, follicular fluid volume and follicular fluid progesterone, oestradiol- $17 \beta$ and testosterone concentrations were determined following the procedures of Foxcroft et al. (1987). Intra- and interassay coefficients of variation for the radioimmunoassays were $3.8 \%$ and $9.4 \%$ for progesterone, $5.5 \%$ and $12.1 \%$ for oestradiol $-17 \beta$ and $6.2 \%$ and $15.4 \%$ for testosterone, respectively.

Collection and fixation of oocytes. After isolation of cumulus-enclosed oocytes using a fine-bore Pasteur pipette, the cumulus cells were dispersed by the addition of $0 \cdot 1 \%$ hyaluronidase (Sigma Chemical Co.) in Hanks balanced salt solution; the oocyte was then fixed in acetic alcohol $(1: 3, v / v)$ and stained with Lacmoid (Sigma Chemical Co., $1 \%$ lacmoid and $45 \%$ acetic acid). The stage of nuclear maturation of oocytes was assessed by phase-contrast microscopy following the classification of Hunter \& Polge (1966).

Statistical analysis. Analysis of variance of transformed and un-transformed data, as appropriate, was used to assess significant differences between mean values of follicular characteristics for naturally cyclic and gonadotrophintreated prepubertal gilts. Correlation analysis was used to determine the relationship between the stage of oocyte maturation and various follicular characteristics. The heterogeneity or variance of follicular characteristics between cyclic and gonadotrophin-treated prepubertal gilts was compared by analysis of variance, assuming that the independently estimated variances followed a gamma distribution.

\section{Results}

The mean number of antral follicles $>2 \mathrm{~mm}$ in diameter for pigs in each group is shown in Fig. 1 . The significant decrease $(P<0.05)$ in the number of follicles recovered from cyclic pigs as folliculogenesis progressed was not observed in gonadotrophin-treated prepubertal gilts. Also, in the early 


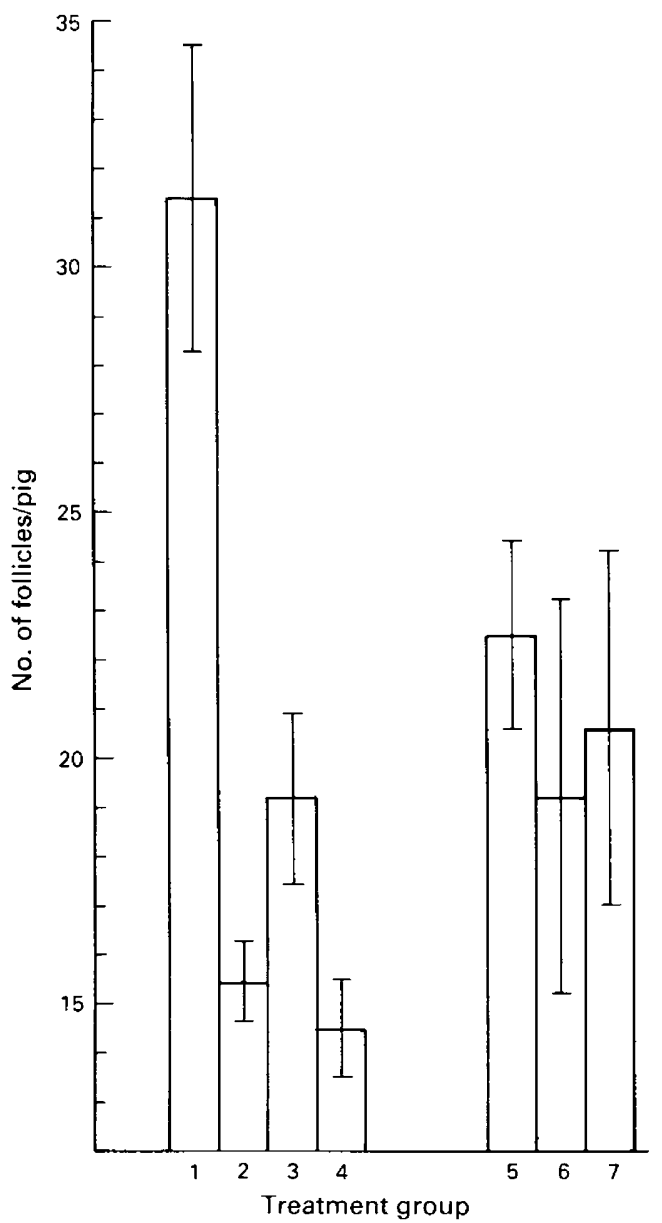

Fig. 1. The mean ( \pm s.e.m. number of follicles $>2 \mathrm{~mm}$ in diameter recovered from the ovaries of naturally cyclic gilts in the early (Group 1), mid (Group 2 and 3) and late (Group 4) follicular phase and after PMSG (Group 5 and 6) or PMSG/hCG (Group 7) stimulation of prepubertal gilts.

phase of follicular development, the ovaries of gonadotrophin-treated prepubertal gilts contained fewer follicles than did those of naturally cyclic pigs (Groups 5 and $1 ; P<0.05$ ).

The distribution of follicles in different size classes in the two groups of gilts at the same stage of development were similar (Fig. 2). Numerous small to medium size follicles ( $<6 \mathrm{~mm}$ in diameter) were present in Groups 1 and 5 (the early follicular phase), and follicles $>8 \mathrm{~mm}$ in diameter were mainly present in Groups 4 and 7 (preovulatory period). Nevertheless, exogenous gonadotrophin treatment resulted in increased $(P<0.001)$ variability in both follicular diameter and volume; the coefficients of variation were $16 \cdot 1$ and 21.4 for diameter and $39 \cdot 18$ and 63.26 for follicular fluid volume in cyclic and gonadotrophin-treated prepubertal gilts, respectively.

Figure 3 presents appropriate group comparisons between cyclic and gonadotrophin-treated prepubertal gilts for different follicle size classes and for the different follicle characteristics measured.

Volume. During the time of follicular recruitment (Groups 1 and 5), follicular fluid volume was similar in each category of follicles in all pigs. However, differences between groups were observed during the time of selection and particularly in the larger, 6-7.9 mm (category III) and $>8.00 \mathrm{~mm}$ 


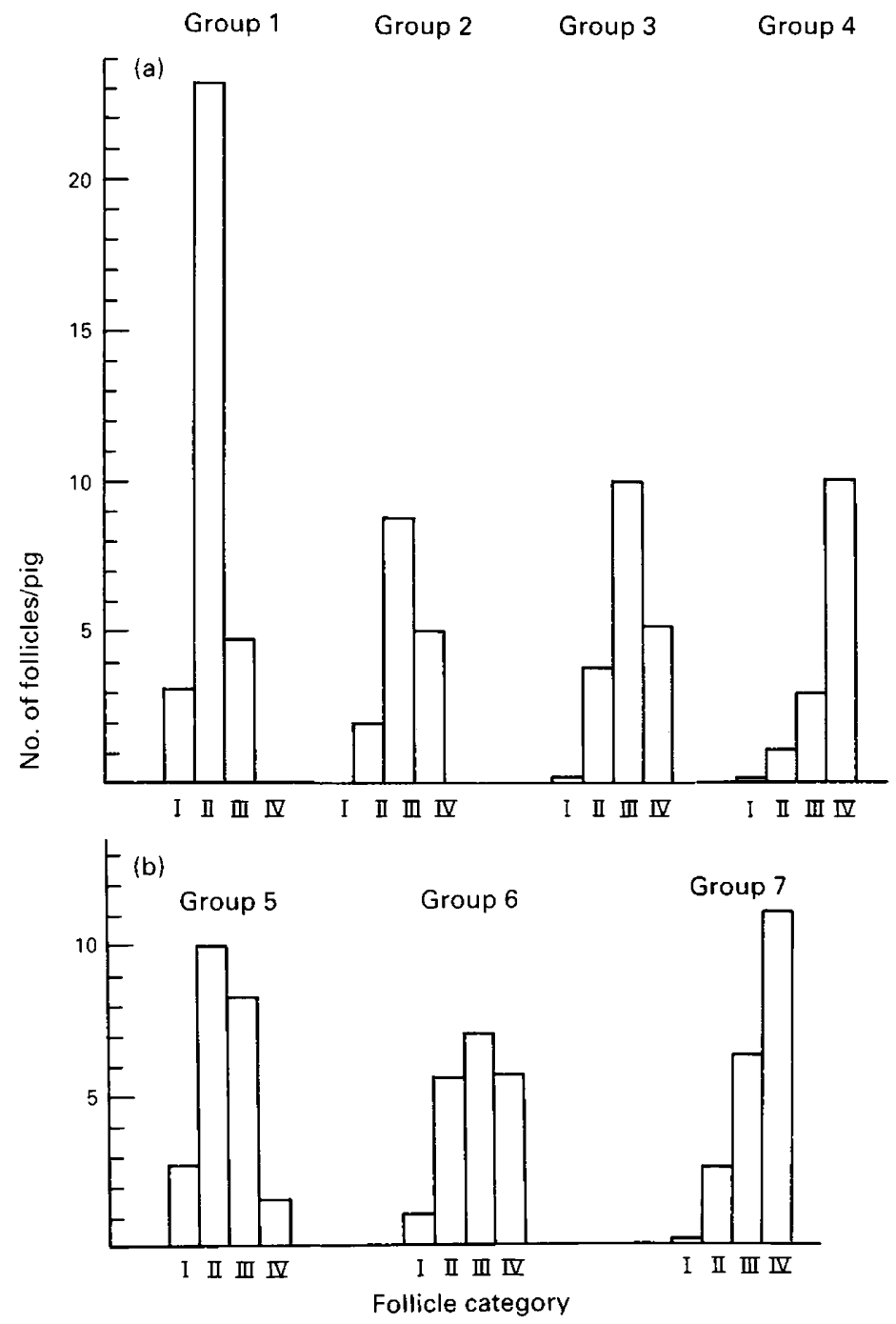

Fig. 2. The distribution of follicles in various size categories from (a) mature cyclic (Groups 1-4) and (b) gonadotrophin-treated prepubertal (Groups 5-7) gilts. Follicle category $\mathbf{I}=$ $2-3.9 \mathrm{~mm} ; \mathrm{II}=4-5.9 \mathrm{~mm}$; III $=6-7.9 \mathrm{~mm}$; IV $=>8.0 \mathrm{~mm}$.

(category IV) follicles. Volume of follicular fluid for gonadotrophin-treated prepubertal gilts was less than for follicles of a similar size from cyclic pigs $(P<0.01$ and $P<0.001$, respectively).

Progesterone. In cyclic gilts follicular fluid progesterone concentrations in the 6-7.9 mm follicles (category III) were lower $(P<0.05$ at least $)$ than in follicles from gonadotrophin-treated prepubertal gilts at all stages of development. A similar reduction in follicular fluid progesterone concentrations in the population of largest follicles (categories III and IV) was only present during the preovulatory period (Group 4 vs Group 7; $P<0.001$ ).

Oestradiol. Mean follicular fluid oestradiol concentrations in cyclic pigs were higher than in gonadotrophin-treated prepubertal gilts during the preovulatory period Group 3 vs Group 6 and Group 4 vs Group 7). Significant $(P<0.001)$ differences between these groups were present in the $6-7.9 \mathrm{~mm}$ (category III) and $>8.0 \mathrm{~mm}$ (category IV) follicles, with differences $(P<0.05)$ also in the 4-5.9 $\mathrm{mm}$ (category II) follicles between Groups 3 and 6 . 


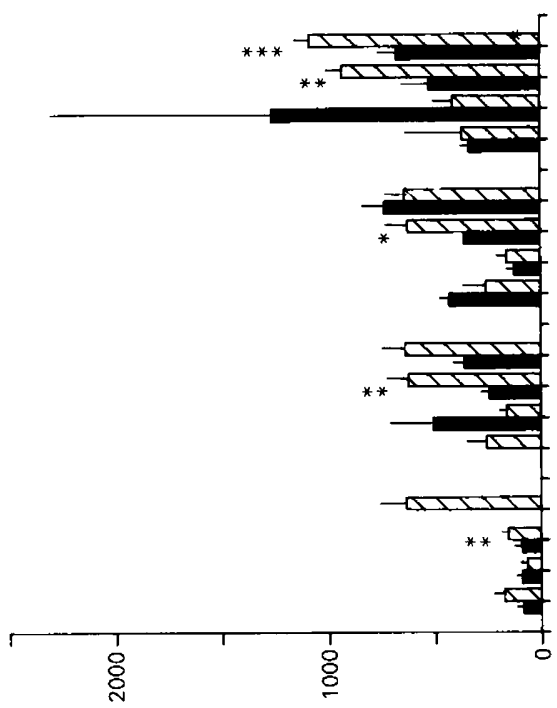

(ןu/6u) aนoגəısa6odd

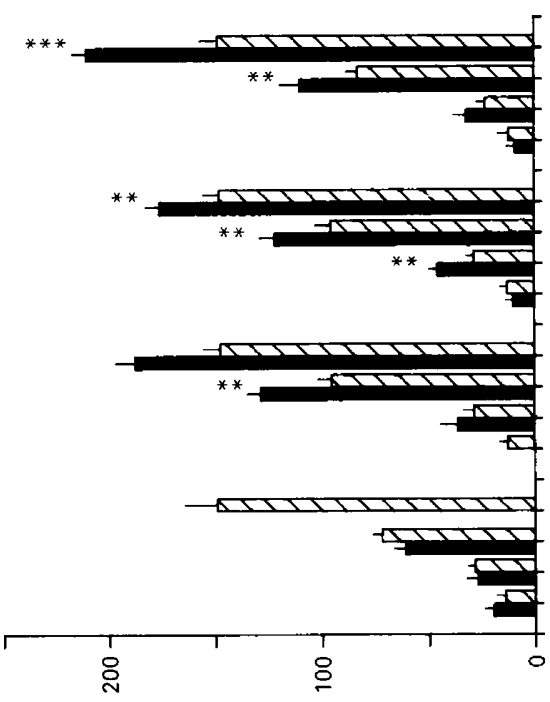

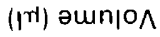

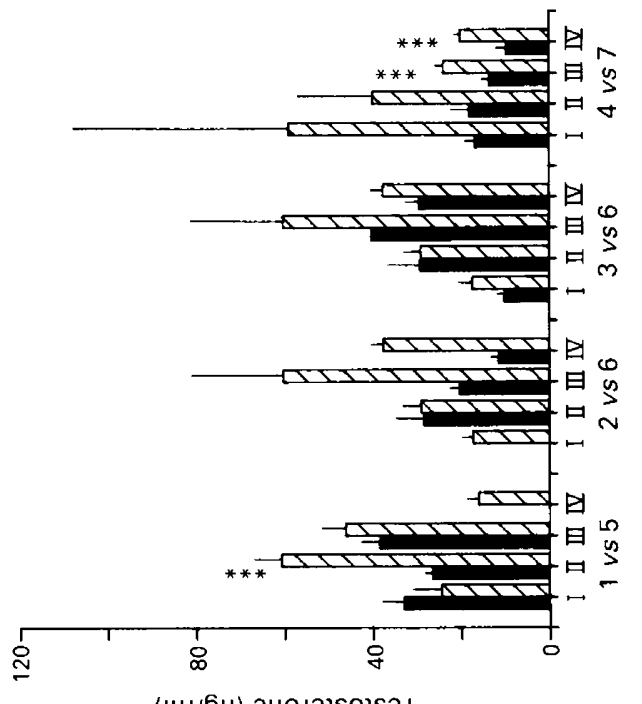

(ןu/6u) əuoมวเsolsə $\perp$

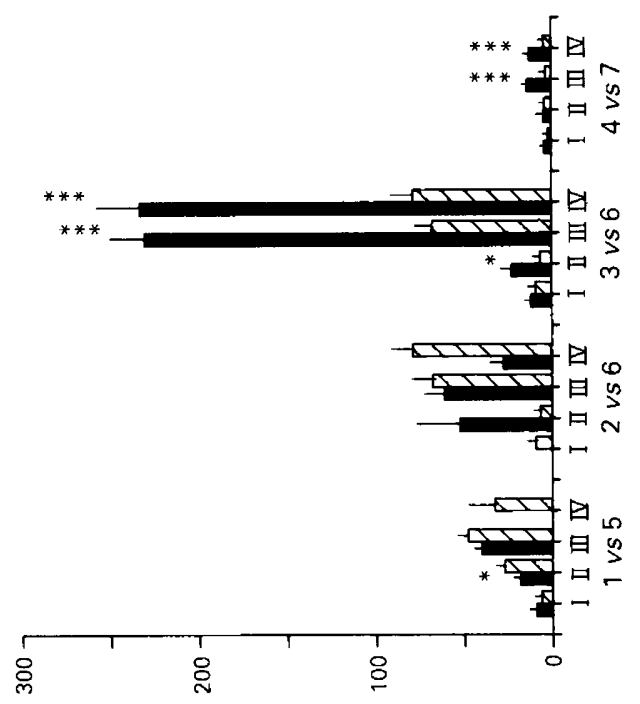

(ןu/6u) $\delta \angle \mathfrak{l}-10 ! p e d \imath s \theta 0$
훙 훙

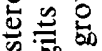

क

$\overrightarrow{\mathcal{E}} \mathrm{F} \&$

0 的要

윽

$\infty$ 응

ㄷํㅇㅇㅛ

$\circ \Delta$

\%

क

\&

훙

흔

훙

용

赵

ㄴ.

a

올

우

สั

氞

잉

$7^{*}$

E*

त

ษ 于े

实 $v$

吸

政

苛宁

$= \pm$

3.

응

○ d

ह

ए :

$+1 \equiv$

$+1.0$

동

$\sum$ 西

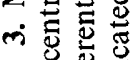

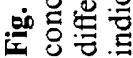



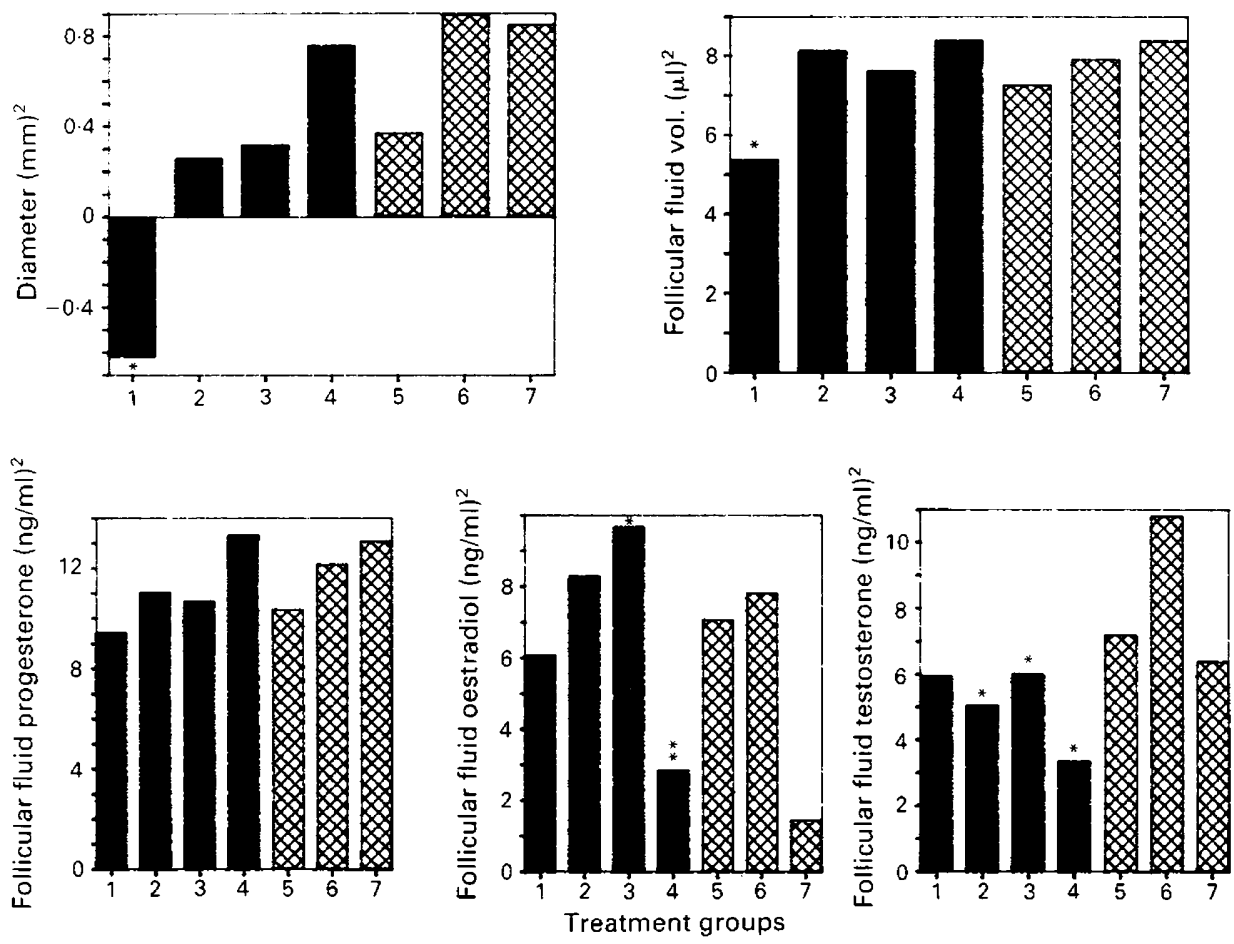

Fig. 4. Calculated log variances in morphological and biochemical characteristics of follicles and follicular fluid for cyclic ( $\mathbf{G}$ Groups 1-4) and gonadotrophin-treated prepubertal ( Groups 5-7) gilts. ${ }^{*} P<0.05 ;{ }^{* *} P<0.01$; when comparing Groups 1 and 5 , Groups 2 and 6 , Groups 3 and 6 and Groups 4 and 7, respectively.

Table 1. Stage of maturation of oocytes recovered from cyclic pigs after the $\mathbf{L H}$ surge (Group 4) and after PMSG/hCG stimulation of prepubertal females (Group 7)

\begin{tabular}{lccrrrrrrr}
\hline & & \multicolumn{6}{c}{$\begin{array}{c}\text { Distribution of oocytes (\%) at different } \\
\text { stages of maturation }\end{array}$} \\
\cline { 4 - 9 } Group & $\begin{array}{c}\text { No. of } \\
\text { follicles }\end{array}$ & $\begin{array}{c}\text { No. of } \\
\text { oocytes }\end{array}$ & $\mathrm{GV}$ & $\mathrm{PM}$ & $\mathrm{M}_{1}$ & $\mathrm{~A}_{1}$ & $\mathrm{~T}_{1}$ & $\mathrm{M}_{2}$ \\
\hline 4 & 87 & 60 & $3 \cdot 3$ & $18 \cdot 3$ & $23 \cdot 3$ & $25 \cdot 0$ & 16.6 & $18 \cdot 3$ \\
7 & 206 & 121 & $42 \cdot 1$ & 4.9 & 6.6 & $19 \cdot 8$ & 4.9 & 21.4 \\
\hline
\end{tabular}

$\mathrm{GV}=$ germinal vesicle $\mathbf{P M}=$ prometaphase $\mathrm{M}_{1}=$ first metaphase; $\mathrm{A}_{1}=$ first anaphase; $T_{1}=$ first telophase; $M_{2}=$ second metaphase.

Testosterone. Mean follicular fluid testosterone concentrations were similar between cyclic and gonadotrophin-treated prepubertal gilts in the preovulatory period. In contrast to those in the gonadotrophin-treated prepubertal gilts, follicular fluid testosterone values declined during the preovulatory phase in cyclic gilts. In the preovulatory period therefore, follicular fluid testosterone concentrations in some follicle size categories of gonadotrophin-treated prepubertal gilts were significantly greater than in follicles from cyclic pigs $(6-7.9 \mathrm{~mm}$, category III, $P<0.001$; $>8.0 \mathrm{~mm}$, 
category IV $P<0.001$ ). Figure 4 shows the distribution of variances in morphological and biochemical development within groups. The variability in both diameter and volume of follicular fluid increased progressively during the follicular phase of the cycle and after exogenous gonadotrophin treatment. Nevertheless, when the variances between groups were compared, then the variances for follicular diameter and volume of Group 5 pigs were greater $(P<0.05)$ than those for Group 1. There were no differences in variances of follicular fluid progesterone between cyclic and gonadotrophin-treated prepubertal gilts. However, in cyclic pigs of Groups 3 and 4, there was greater variance in follicular fluid oestradiol than in gonadotrophin-treated prepubertal gilts of Groups 6 and $7(P<0.05$ and $P<0.01$, respectively). Exogenous gonadotrophin treatment affected the variability of follicular fluid oestradiol concentrations $(P<0.001)$; the coefficients of variation for cyclic and gonadotrophin-treated prepubertal gilts being 61.0 and $72.0 \%$, respectively. In direct contrast, the variance in follicular fluid testosterone for gonadotrophin-treated prepubertal gilts was greater than in cyclic pigs (Group 2 vs Group 6, Group 3 vs Group 6 and Group 4 vs Group 7; $P<0.05)$.

Before oestrus in cyclic animals or hCG stimulation of prepubertal gilts, all recovered oocytes were identified as being in the intact germinal vesicle stage. After the onset of oestrus or hCG administration (Groups 4 and 7), expansion of the cumulus had occurred in most follicles and the oocyte had undergone maturation (Table 1). There was considerable variability even in individual animals in the stage of oocyte maturation in both gonadotrophin-treated prepubertal and cyclic pigs. Overall this variability was greater in gonadotrophin-treated prepubertal than cyclic pigs, $(P<0.05)$. The stage of oocyte maturation was significantly $(r=0.33)(P<0.05)$ correlated with follicular fluid volume in cyclic pigs and with follicular diameter $(r=0.24)(P<0.05)$ in the PMSG/hCG-treated prepubertal gilts.

\section{Discussion}

The pattern of follicular development observed in the present study in the cyclic pig was consistent with changes in the numbers of follicles in various size categories demonstrated previously (Grant et al., 1989). Treatment of prepubertal gilts with PMSG/hCG also induced follicular growth as described previously (Ainsworth et al., 1980; Paterson, 1982). Ainsworth et al. (1980) reported that the ovaries of PMSG-primed gilts contained a uniform population of developing follicles 24 and $48 \mathrm{~h}$ after PMSG injection. The analyses of the results of the present study, however, established a considerable range of follicular development even $36 \mathrm{~h}$ after PMSG treatment. This discrepancy may be related to the measurement of only a representative number of follicles on each ovary at laparotomy by Ainsworth et al. (1980), and in most cases the follicular fluid collected from accessible follicles was pooled. Furthermore, the present study showed that exogenous gonadotrophin treatment significantly affected the variability in follicular diameter and follicular fluid volume. Such differences could be a consequence of changes in the morphological development of follicles, such as the reported infolding of the granulosa and theca layer in the late follicular phase (Corner, 1919; Bagnell et al., 1987; Hunter et al., 1989). Overall, our data demonstrate that the pattern of follicular growth in gonadotrophin-stimulated prepubertal gilts is markedly different from that in naturally cyclic females.

Foxcroft \& Hunter (1985) proposed that in cyclic pigs dominant follicles may promote the maturation of smaller follicles, in contrast to their inhibitory effect in other species (Driancourt $\&$ Fry, 1988; Fortune \& Quirk, 1988). Such effects may be mediated by a local action of ovarian steroids as reported by Richards et al. (1978), who demonstrated that changes in the endogenous production of oestradiol and/or the response of follicular cells to oestrogen may affect the rate of follicular growth and the differentiation of follicular cells. The paracrine machanisms and local vascular pathways that would allow steroids to exert such effects were reviewed by Foxcroft $\&$ Hunter (1985). Therefore, given the established role for ovarian steroids in regulating the pattern of 
follicular development, it is likely that the differences in follicular fluid oestradiol and testosterone concentrations in gonadotrophin-treated prepubertal compared to cyclic gilts observed in the present study would have been of functional significance. The observation that differences in steroid content were particularly evident in the larger preovulatory follicles is also consistent with the concept that these follicles have a critical role in regulating the pattern of follicular growth within the ovary.

Additional evidence that differences in the steroidogenic, as well as morphological, development of follicles after PMSG/hCG stimulation of prepubertal gilts may be functionally important comes from reports that after ovulation the corpora lutea of prepubertal PMSG/hCG-stimulated gilts differed from the corpora lutea of cyclic pigs (Kineman et al., 1987a, b). The progesterone metabolic pathway either appears to be different in the induced corpora lutea of prepubertal gilts or the luteal tissue is less sensitive to gonadotrophic stimulation. Further evidence of altered luteal function is the reported inability of gonadotrophin-treated prepubertal gilts to maintain pregnancy to 25 days after induced ovulation (Shaw et al., 1971; Segal \& Baker, 1973; Rampacek et al., 1976). Again this was presumably due to inadequate steroid production because pregnancy can be maintained in prepubertal gilts by administration of steroids or gonadotrophins (Shaw et al., 1971; Ellicott et al., 1973; Segal \& Baker, 1973; Rampacek et al., 1976). Although no direct comparisons were made between cyclic and gonadotrophin-treated females in the studies of Babalola \& Shapiro (1988) and Grant et al. (1989), these authors also suggested that the pattern of ovarian steroidogenesis reported for follicles from PMSG/hCG-treated gilts was different from those observed in naturally cyclic females.

The present study also confirms previous suggestions (Foxcroft et al., 1987; Hunter et al., 1989) that morphological features alone cannot be used to characterize follicle populations effectively. Although the variances in morphological characteristics were similar in the present study, variances in biochemical characteristics were different. The present data also confirm the observations of Foxcroft et al. (1987), Grant et al. (1989) and Hunter \& Wiesak (1990) that, even in the selected preovulatory population, follicles of identical size may show great dissimilarity in follicular fluid steroid concentration.

The timing of the resumption of meiosis and the sequence of maturational changes in the recovered oocytes (Table 1) are similar to those observed in the mature pig (Spalding et al., 1955) and after a single injection of hCG (Hunter \& Polge, 1966), and the resumption of meiosis was associated with a low oestradiol-17 $/$ progesterone ratio in follicular fluid. Although there were some differences in the stages of oocyte maturation in cyclic and gonadotrophin-treated prepubertal gilts, these may have been due to the time of oocyte recovery in relation to the endogenous $\mathrm{LH}$ surge or hCG stimulation. Oocytes of gonadotrophin-treated prepubertal gilts were recovered between 35 and $40 \mathrm{~h}$ after hCG injection, while oocytes of cyclic pigs were recovered at an undefined time after the endogenous LH surge. However, the possibility that differences in the pattern and rate of oocyte maturation were a direct consequence of the observed difference in follicular development merits further study. This difference in follicular development may also influence subsequent early embryonic development, and indeed Pinkert et al. (1989) have reported that zygotes resulting from PMSG/hCG-treated prepubertal gilts did not possess the same capacity for in-vitro development as did zygotes from pubertal gilts.

In conclusion, this study confirms the suggestions of Hunter \& Wiesak (1990) that the growth and development of follicles in this polyovulatory species are complex and are normally associated with considerable variability in even the selected preovulatory follicle population. Furthermore, the results suggest that conclusions on the control of ovarian function derived from the study of PMSG/hCG-primed females may not represent the true physiological situation in naturally cyclic animals.

This work received financial support from the AFRC and from the Journal of Reproduction and Fertility Ltd (Postdoctoral Fellowship to T.W.). We thank Dr S. Lynch for antisera; and Mrs V. Watt and Mrs S Woodward for technical assistance. 


\section{References}

Ainsworth, L., Tsang, B.K., Downey, B.R., Marcus, G.J. \& Armstrong, D.T. (1980) Interrelationships between follicular fluid steroid levels, gonadotropic stimuli and oocyte maturation during preovulatory development of porcine follicles. Biol. Reprod. 23, 621-627.

Babalola, G.O. \& Shapiro, B.H. (1988) Correlation of follicular steroid hormone profiles with ovarian cyclicity in sows. J. Reprod. Fert. 84, 79-87.

Bagnell, C.A., Frando, L.B., Downey, B.R., Tsang, B.K. \& Ainsworth, L. (1987) Localization of relaxin in the pig follicle during preovulatory development. Biol. Reprod. 37, 235-240.

Christenson, R.K., Ford, J.J. \& Redmer, D.A. (1985) Maturation of ovarian follicles in the prepubertal gilt. J. Reprod. Fert., Suppl. 33, 21-36.

Corner, G.W. (1919) On the origin of the corpus luteum of the sow from both granulosa and theca interna. Am. J. Anat. 26, 117-183.

Driancourt, M.A. \& Fry, R.C. (1988) Differentiation of ovulatory follicles in sheep. J. Anim. Sci. 66 (Suppl. 2), 9-20.

Ellicott, A.R., Dziuk, P.J. \& Polge, C. (1973) Maintenance of pregnancy in prepuberal gilts. J. Anim. Sci. $37,971-973$.

Fortune, J.E. \& Quirk, S.M. (1988) Regulation of steroidogenesis in bovine preovulatory follicles. $J$. Anim. Sci. 66 (Suppl. 2), 1-8.

Foxcroft, G.R. \& Hunter, M.G. (1985) Basic physiology of follicular maturation in the pig. $J$. Reprod. Fert., Suppl. 33, 1-19.

Foxcroft, G.R., Shaw, H.J., Hunter, M.G., Booth, P.J. \& Lancaster, R.T. (1987) Relationships between luteinizing hormone, follicle-stimulating hormone and prolactin secretion and ovarian follicular development in the weaned sow. Biol. Reprod. 36, 175-191.

Grant, S.A., Hunter, M.G. \& Foxcroft, G.R. (1989) Morphological and biochemical characteristics during ovarian follicular development in the pig. J. Reprod. Fert. 86, 171-183.

Hunter, M.G. \& Wiesak, T. (1990) Evidence for and implications of follicular heterogeneity in pigs. $J$. Reprod. Fert., Suppl. 40, 163-177.

Hunter, M.G., Grant, S.A. \& Foxcroft, G.R. (1989) Histological evidence for heterogeneity in the development of preovulatory pig follicles. J. Reprod. Fert. 86, 165 170.
Hunter, R.M.F. \& Polge, C. (1966) Maturation of follicular oocytes in the pig after injection of human chorionic gonadotrophin. J. Reprod. Fert. 12, 525531 .

Kineman, R.D., Kraeling, R.R., Rampacek, G.B. \& Hausman, G.J. (1987a) Comparison of induced corpora lutea from prepubertal gilts and spontaneous corpora lutea from mature gilts: hydroxysteroid dehydrogenase activity. J. Anim. Sci. 64, 237-240.

Kineman, R.D., Rampacek, G.B., Kraeling, R.R., FiorelloStocks, N.A. \& Wilson, R.L. (1987b) Comparison of induced corpora lutea from prepuberal gilts and spontaneous corpora lutea from mature gilts: in vitro progesterone production. J. Anim. Sci. 64, 526-532.

Paterson, A.M. (1982) The controlled induction of puberty. In Control of Pig Reproduction, pp. 139-159. Eds D. J. A. Cole \& G. R. Foxcroft. Butterworths Scientific, London.

Pinkert, C.A., Kooyman, D.L., Baumgartner, A. \& Keisler, D.H. (1989) In-vitro development of zygotes from superovulated prepubertal and mature gilts. $J$. Reprod. Fert. 87, 63-66.

Rampacek, G.B., Schwartz, F.L., Fellows, R.E., Robison, O.W. \& Ulberg, L.C. (1976) Initiation of reproductive function and subsequent activity of the corpora lutea in prepuberal gilts. J. Anim. Sci. 42, 881887.

Richards, J.S., Rao, M.C. \& Ireland, J.J. (1978) Actions of pituitary gonadotrophins on the ovary. In Control of Ovulation, pp. 197-216. Eds D. B. Crighton, N. B. Haynes, G. R. Foxcroft \& G. E. Lamming. Butterworth Scientific, London.

Segal, D.H. \& Baker, R.D. (1973) Maintenance of corpora lutea in prepuberal gilts. J. Anim. Sci. 37, 762767.

Shaw, G.A., McDonald, B.E. \& Baker, R.D. (1971) Fetal mortality in the prepuberal gilt. Can. J. Anim. Sci.51, 223-236.

Spalding, J.F., Berry, R.O. \& Moffit, J.G. (1955) The maturation process of the ovum of swine during normal and induced ovulations. J. Anim. Sci. 14, $609-620$. 